\title{
EFSUMB January Webinar
}

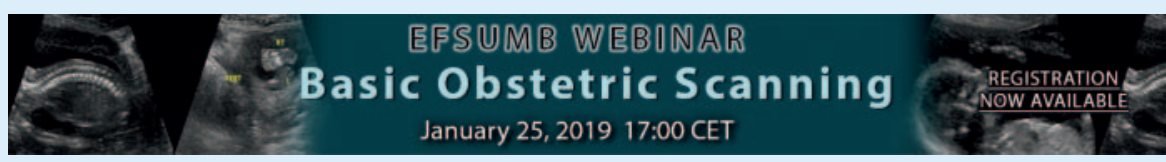

If you missed the webinar you can watch it in the EFSUMB webinar archive http://www. efsumb.org/blog/webinar-archive-2
First trimester scan

Themistoklis Dagklis
Second trimester scan

Panos Antsaklis

Ultrasound assessment of growth

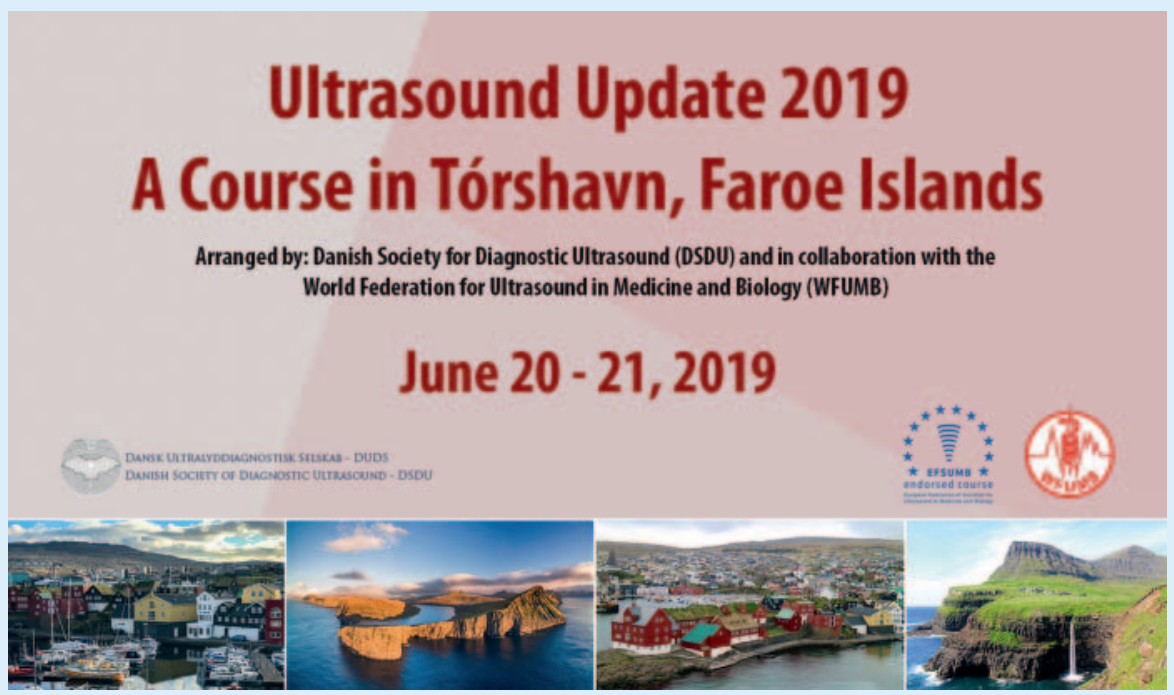



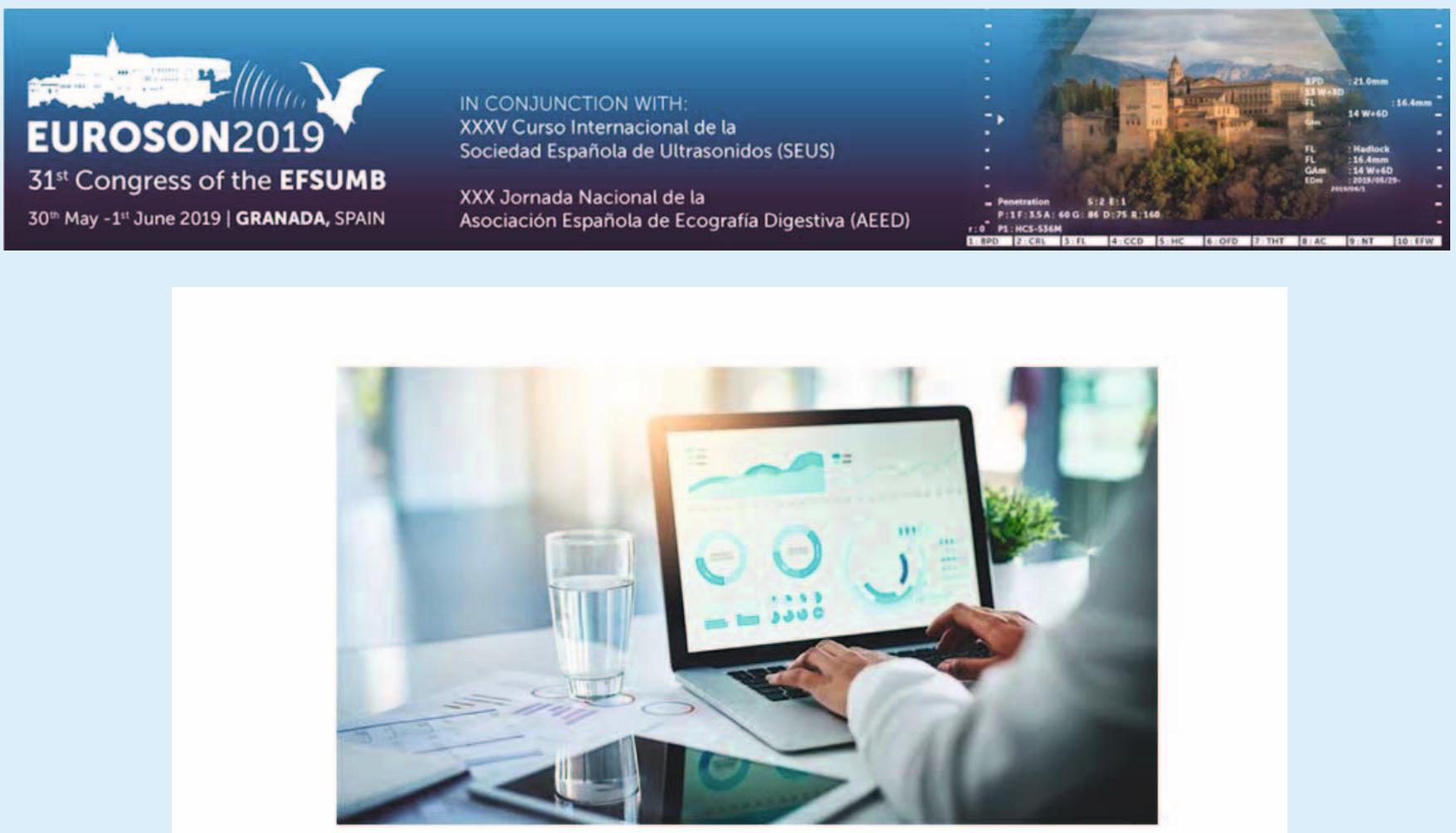

Check the new details of the program!

Do not hesitate to submit your abstract for EUROSON 2019 and be part of a leading. groundbreaking scientific program in ultrasound. Submission guidelines can be found on the website, accessing through the link below.

Abstract Submission Deadline: March 5th 2019

\section{Discover the latest updates on the program}

We are working on a scientific program with cutting-edge sessions, workshops and

conferences. Check the program and access to each session to see the topic and lecture details.

* GET A 15\% DISCOUNT ON YOUR FLIGHT RESERVATIONS TO GRANADA WITH ONEWORLD

To book tour trip, visit the following link: https://events.oneworld.com/ and enter the Event ID at the "attendee" section: OW07A19 


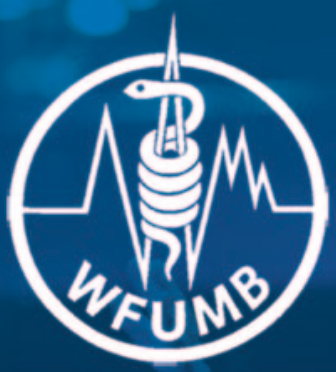

\section{The 17th World Federation for Ultrasound in Medicine and Biology Congress}

hosted by the Australasian Society for Ultrasound in Medicine

Friday 6 September to Monday 9 September 2019

Melbourne Convention and Exhibition Centre

VICTORIA, AUSTRALIA

Join over 2,000 delegates and network with world renowned professionals at an international platform.

The World Congress will feature the largest multi-disciplinary ultrasound-focussed program in Australia.

Anaesthetics $\cdot$ Breast $\cdot$ Cardiac $\cdot$ CEUS $\cdot$ Critical Care $\cdot$ Education $\cdot$ Emergency medicine Fetal heart $\cdot$ Fetal neurosonography $\cdot$ General ultrasound $\cdot$ Gynaecology $\cdot$ Men's health MSK $\cdot$ Neonatal $\cdot$ Obstetrics $\cdot$ Paediatrics $\cdot$ PoCUS $\cdot$ Rheumatology $\cdot$ Vascular $\cdot$ Ethics Infection prevention $\cdot$ Professional practices

Lectures, Live scanning and Workshops.

There's something for everyone, don't miss out.

Be part of the World Congress for Ultrasound and see you in Melbourne!

KEY DATES

3 December 2018 Registrations open

1 March $2019 \quad$ Call for abstracts closes

1 May $2019 \quad$ Early bird registration closes

6 September 2019 WFUMB 2019 opens

REGISTER NOW FOR EARLY BIRD TICKETS

\section{wfumb2019.org}

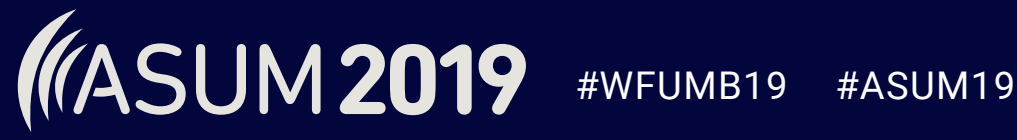

